\title{
Epidemiology, diagnostic and management of abdominal trauma in two hospitals in the city of Douala, Cameroon
}

\author{
Jean Paul Engbang1,2*, Christian Beughuem Chasim ${ }^{3}$, Bekolo Fouda',4, Mathieu Motah ${ }^{1,3}$, \\ Thomas Jim Kevin Moukoury ${ }^{1}$, Marcelin Ngowe Ngowe ${ }^{1,5}$
}

\author{
${ }^{1}$ The University of Douala, Douala, Cameroon \\ ${ }^{2}$ Douala Laquintinie Hospital, Douala, Cameroon \\ ${ }^{3}$ Douala General Hospital, Douala, Cameroon \\ ${ }^{4}$ Douala Military Hospital, Douala, Cameroon \\ ${ }^{5}$ The University de Yaounde I, Yaounde, Cameroon
}

Received: 10 April 2021

Revised: 17 May 2021

Accepted: 18 May 2021

\section{*Correspondence: \\ Jean Paul Engbang, \\ E-mail: jean_pen@yahoo.ca}

Copyright: (C) the author(s), publisher and licensee Medip Academy. This is an open-access article distributed under the terms of the Creative Commons Attribution Non-Commercial License, which permits unrestricted non-commercial use, distribution, and reproduction in any medium, provided the original work is properly cited.

\begin{abstract}
Background: Abdominal trauma remains quite common in the general world and in developing countries in particular. The accidents in the public roads are the main cause and also the assumption of responsibility which remains questionable.

Methods: It was a descriptive longitudinal study, carried out from 31 December 2018 to 19 April 2019, in Laquintinie and General hospital in Douala, Cameroon. Patients admitted for abdominal trauma and treatment in the emergency department, operating theater and visceral surgery were included in the study.

Results: We found $21.2 \%$ (43 cases) of abdominal trauma in our series. Abdominal trauma mainly affected adults between 20 and 39 years old $(27$ cases, $63 \%)$ in our series. The male sex was most affected, with sex ration of 3.3 . Road accidents occupy the first place with $34.9 \%$ (15 cases). Wounds in our series represented $27.9 \%$ (12 cases) and contusions $72.1 \%$ (31 cases). In fact, Abdomen without preparation was performed in $7.0 \%$ (3 cases) of cases, abdominal ultrasound in $48.8 \%$ (21 cases) and abdominal CT scan in $25.6 \%$ of patients (11 cases). The organs affected in order were the spleen, small intestine, colon, stomach and liver. We recorded postoperative complications with a morbidity of $11.6 \%$ with a single case of parietal suppuration and no death.

Conclusions: In our context abdominal trauma remains quite frequent and concern particularly young people. The prevention of accidents on the public highway and the improvement of diagnostic and surveillance methods are the key for reducing this phenomenon leading to good management.
\end{abstract}

Keywords: Abdominal trauma, Epidemiology, Diagnostic, management, Cameroon

\section{INTRODUCTION}

Trauma in general is one of the most common causes of morbidity and mortality, particularly among young people. ${ }^{1,2}$ Severe abdominal trauma in adults accounts for $15-20 \%$ of traumatic injuries. ${ }^{3}$ According to the literature, the most frequent cause of these injuries remains road accidents, followed by assaults. ${ }^{2,4}$ These attacks of the abdomen are isolated in 30 to $40 \%$ of cases and can be integrated in a context of multiple trauma. ${ }^{5}$ The most common cause of death in patients who die early after severe trauma is haemorrhage ( $>80 \%$ of cases), death is considered preventable half of the time and the lesion location considered to be the cause of death is the abdomen in $53 \%$ of cases. ${ }^{6}$ commonly injured organs are the spleen, bowels, stomach, and liver, with the least 
frequently injured organs being the diaphragm and kidney. These injuries that could be blunt or penetrating require careful triaging for appropriate intervention because approximately $25 \%$ of such injuries require surgery. ${ }^{7,8}$

It is difficult to find studies that have been devoted to this pathology in Cameroon. This is the reason why we decided to study the epidemiological, clinical, therapeutic and evolutionary characteristics of abdominal trauma in two hospitals in the city of Douala.

\section{METHODS}

This was a descriptive longitudinal study, which took place in 2 hospitals in the city of Douala, in particular at the Laquintinie Hospital and at the General Hospital, in the services of emergencies, operating theater and visceral surgery. Were included, all patients admitted for abdominal trauma and treatment in these health facilities from 31 December 2018 to 31 May 2019. After obtaining the authorizations, recruitment was done from patients presenting with an emergency digestive surgical presentation, and among them, were chosen those who had been received for abdominal trauma in our two study centers.

All the outlines of the study were explained to them in order to obtain their informed consent. Thus, were included in our study, patients of all ages and of both sexes who presented with confirmed abdominal trauma, and who had undergone surgery in one of our study centers.

In addition to those who did not give their consent, those patients who had gynecological and urological trauma were excluded.
A data collection sheet was designed and completed by the investigator. The variables sought were age, sex, patient complaints, hemodynamic parameters, different clinical and functional signs, biological and radiological data, different types of interventions and organs affected, postoperative follow-up. These parameters were analyzed using SPSS software version 23.0

This work had received an ethical clearance from the Ethics Committee of the University of Douala.

\section{RESULTS}

\section{Epidemiology}

\section{Frequency}

The figure below shows us that five aetiologies constituted the bulk of digestive surgical emergencies with appendicular syndrome in the lead (24.6\%) followed by peritoneal syndromes and traumatic abdomens (respectively $22.7 \%$ and $21.2 \%$ ). Bowel obstructions represented $18.2 \%$ of the target population, and strangulated hernias $13.3 \%$.

\section{Age and sex}

Out of a total of 43 patients, the male sex was in the majority with 33 cases $(70.7 \%)$, i.e. a sex ratio of $\mathrm{M} / \mathrm{F}$ : 3.3 The average age was $31.7 \pm 5.4$ years, with the extremes of 15 and 67 years. The 30-39 years old age group had the largest enrollment (17 cases, 39.5\%) (Table 1).

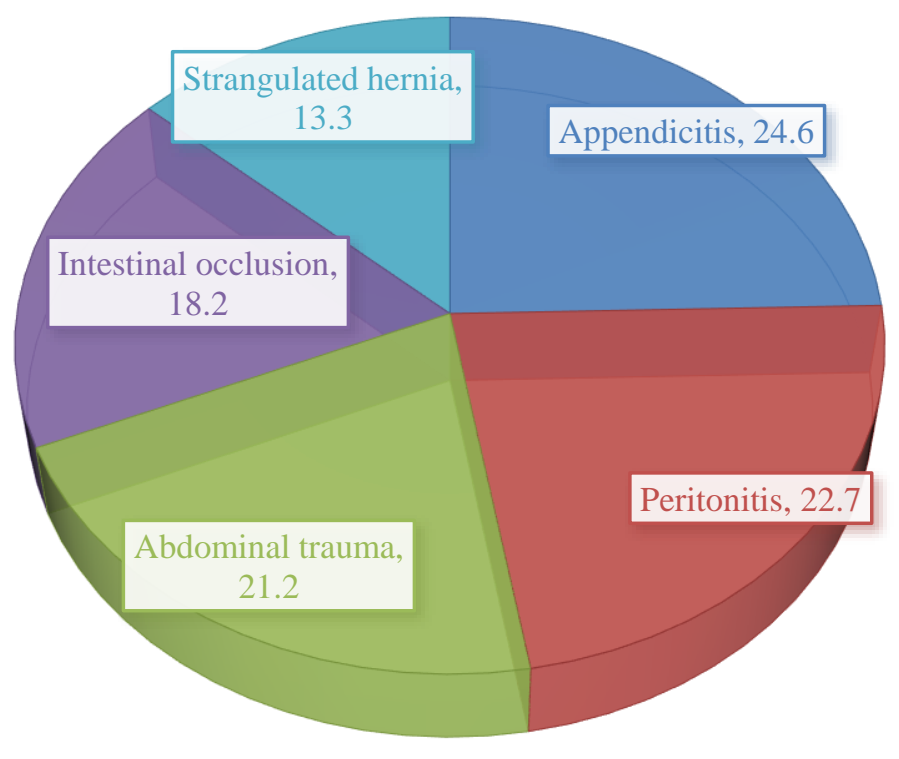

Figure 1: Distribution of clinical pictures in digestive emergencies. 
Table 1: Distribution according to age groups.

\begin{tabular}{|c|c|c|c|}
\hline $\begin{array}{l}\text { Age } \\
\text { (years) }\end{array}$ & group & Effective (N) & Percentage $(\%)$ \\
\hline $10-19$ & & $6(13,9)$ & 13.9 \\
\hline $20-29$ & & $10(23,5)$ & 23.5 \\
\hline 30-39 & & $17(39,5)$ & 39.5 \\
\hline $40-49$ & & $8(18,6)$ & 18.6 \\
\hline $50-59$ & & $1(2,3)$ & 2.3 \\
\hline $60-69$ & & $1(2,3)$ & 2.3 \\
\hline
\end{tabular}

\section{Clinical aspects}

\section{Symptoms}

As shown on Table 2, accident of the public road (APR) was the second reason for consultation in general $(8.4 \%)$, and the main one $(34.9 \%)$ in abdominal trauma. Then came abdominal pain and stab wounds, in $30.2 \%$ and $23.3 \%$ respectively.

Table 2: Installation and location of pain.

\begin{tabular}{|lll|}
\hline \multicolumn{2}{|l|}{ Variables } & \multicolumn{2}{l|}{ Effective (N) } & Percentage (\%) \\
\hline \multicolumn{2}{|l|}{ Reason of consultation } & \\
\hline Post-APR tauma & 15 & 34.9 \\
\hline Abdominal pain & 13 & 30.2 \\
\hline Wound (firearm) & 2 & 4.6 \\
\hline $\begin{array}{l}\text { Wound (bladed } \\
\text { weapon) }\end{array}$ & 10 & 23.3 \\
\hline $\begin{array}{l}\text { Shock } \\
\text { brawl/aggression }\end{array}$ & 2 & 4.6 \\
\hline $\begin{array}{l}\text { Post-operative } \\
\text { complication }\end{array}$ & 1 & 2.3 \\
\hline Mode d'installation & 40 & 93.0 \\
\hline Brutal & 3 & 7.0 \\
\hline Progressive & 1 & 2.3 \\
\hline Location of pain & 1 & 2.3 \\
\hline Epigastrium & 2 & 4.7 \\
\hline Right iliac fossa & 1 & 6.9 \\
\hline Left iliac fossa & 3 & 6.9 \\
\hline Left flank & 3 & 6.9 \\
\hline Peri-umbilical & 3 & 14.0 \\
\hline $\begin{array}{l}\text { Right } \\
\text { hypochondrium }\end{array}$ & 6 & 4.7 \\
\hline $\begin{array}{l}\text { Left } \\
\text { hypochondrium }\end{array}$ & 2 & 30.2 \\
\hline $\begin{array}{l}\text { Hypogastrium } \\
\text { Generalised }\end{array}$ & 13 & \\
\hline
\end{tabular}

\section{Hemodynamic parameters and functional signs}

Five patients $(11.6 \%)$ had high blood pressure, and five others had hypotension on admission. $6.9 \%$ had hypothermia $\left(<36.5^{\circ} \mathrm{C}\right)$. In 28 patients $(65.1 \%)$, we observed tachycardia (>100 bpm), and $48.8 \%$ hyperventilated on admission (Table 3 ).
In abdominal trauma, the main functional signs associated with pain were dyspnea (in 20.9 of the cases), asthenia (11.6\%) and vomiting (9.3\%).

Table 3: Hemodynamic parameters and functional signs.

\begin{tabular}{|c|c|c|}
\hline Variables & Effective (N) & Percentage $(\%)$ \\
\hline \multicolumn{3}{|c|}{ Hemodynamic parameters } \\
\hline \multicolumn{3}{|c|}{ Blood pressure (mm Hg) } \\
\hline$\leq 90 / 160$ & 5 & 11.6 \\
\hline $90 / 60-140 / 90$ & 12 & 27.9 \\
\hline$>140 / 90$ & 5 & 11.6 \\
\hline \multicolumn{3}{|l|}{ Temperature $\left({ }^{\circ} \mathbf{C}\right)$} \\
\hline$<36.5$ & 3 & 6.9 \\
\hline $36.5-38.5$ & 24 & 55.8 \\
\hline$>38.5$ & 16 & 37.2 \\
\hline \multicolumn{3}{|l|}{ Pulse (bpm) } \\
\hline$\leq 100 \mathrm{bpm}$ & 15 & 34.9 \\
\hline$>100 \mathrm{bpm}$ & 28 & 65.1 \\
\hline \multicolumn{3}{|c|}{ Respiratory rate (cpm) } \\
\hline$\leq 20 \mathrm{cpm}$ & 22 & 51.2 \\
\hline$>20 \mathrm{cpm}$ & 21 & 48.8 \\
\hline \multicolumn{3}{|l|}{ Functional signs } \\
\hline Vomiting & 4 & 9.3 \\
\hline Nausea & 3 & 7.0 \\
\hline Dysphagia & 3 & 7.0 \\
\hline Bloating & 2 & 4.7 \\
\hline Diarrhea & 1 & 2.3 \\
\hline $\begin{array}{l}\text { Discontinuation of } \\
\text { materials }\end{array}$ & 3 & 7.0 \\
\hline Constipation & 4 & 9.3 \\
\hline Anorexia & 2 & 4.7 \\
\hline Urinary disorders & 1 & 2.3 \\
\hline Asthenia & 5 & 11.6 \\
\hline Dyspnea & 9 & 20.9 \\
\hline
\end{tabular}

\section{Clinical signs}

On inspection of patients, $27.9 \%$ had pale conjunctivae. Abdominal distension was present in $70.7 \%$ of cases. $58.1 \%$ of the patients presented with a meteorism, localized in $14 \%$ of cases, and diffuse in $46 \%$ (Table 4).

On palpation, 22 patients $(44.9 \%)$ presented abdominal defense. The call of the umbilicus and Mc Burney's sign were the specific signs most often observed, in $11.6 \%$ and $46.5 \%$ of cases, respectively.

On auscultation, hydro-aeric noises were eliminated in $9.4 \%$ of cases.

On percussion, tympanism was perceived in $29.3 \%$ of cases. In the majority of cases $(76.3 \%)$, the digital rectal examination was painless in the patients. 
Table 4: Distribution according to clinical signs.

\begin{tabular}{|c|c|c|}
\hline Variables & Effective (N) & Percentage (\%) \\
\hline \multicolumn{3}{|l|}{ Conjonctiva } \\
\hline Colorful & 31 & 72.1 \\
\hline Pale & 12 & 27.9 \\
\hline Jaundice & 3 & 7.0 \\
\hline \multicolumn{3}{|l|}{ Oral cavity } \\
\hline Wet & 36 & 85.7 \\
\hline Dried & 6 & 14.3 \\
\hline Distended abdomen & 29 & 70.7 \\
\hline \multicolumn{3}{|l|}{ Meteorism } \\
\hline Localiwede & 5 & 11.6 \\
\hline Diffuse & 20 & 46.5 \\
\hline Absent & 18 & 41.9 \\
\hline Defense & 18 & 42.9 \\
\hline \multicolumn{3}{|l|}{ Contracture } \\
\hline Diffuse & 12 & 27.9 \\
\hline Localized & 11 & 25.6 \\
\hline Depressible abdomen & 27 & 65.9 \\
\hline Cry of the umbilicus & 22 & 51.2 \\
\hline Blumberg & 3 & 7.0 \\
\hline Rovsing & 4 & 9.3 \\
\hline McBurney & 3 & 7.0 \\
\hline \multicolumn{3}{|l|}{ Hydro-air noise } \\
\hline Audible & 39 & 90.7 \\
\hline Inaudible & 4 & 9.3 \\
\hline \multicolumn{3}{|l|}{ Percussion } \\
\hline Dullness & 29 & 70.7 \\
\hline Tympanism & 12 & 29.3 \\
\hline \multicolumn{3}{|l|}{ Rectal touch } \\
\hline Paunless & 29 & 76.3 \\
\hline
\end{tabular}

\section{Paraclinic aspects}

\section{Bilogical data}

Among them, $18.6 \%$ presented with hyperleukocytosis $\left(\mathrm{GB}>10,000 / \mathrm{mm}^{3}\right) .25 .6 \%$ had a hemoglobin level below $10 \mathrm{~g} / \mathrm{dl}$.
Thrombocytosis (platelets $>150 \mathrm{~g} / \mathrm{dl}$ ) was observed in $2.3 \%$ of cases. $13.9 \%$ of patients had hyponatremia.

Hypo and hyperkalaemia were observed in $16.3 \%$ and $2.3 \%$ of patients, respectively. $4.6 \%$ of patients had a $\mathrm{CRP}>6 \mathrm{mg} / \mathrm{dl}$.

Table 5: Distribution according to biological signs.

\begin{tabular}{|c|c|c|}
\hline Variables & Effective (N) & Percentage \\
\hline \multicolumn{3}{|l|}{ NFS } \\
\hline \multicolumn{3}{|c|}{ White blood cells, $M \pm$ Ecart-type (per $\mathbf{m m}^{3}$ ) } \\
\hline$<4000$ & - & \\
\hline $4000-10,000$ & 12 & 27.9 \\
\hline$>10000$ & 8 & 18.6 \\
\hline \multicolumn{3}{|c|}{ Red cells, $M \pm$ Ecart-type $\left(\mathrm{M} / \mathrm{mm}^{3}\right)$} \\
\hline$<4$ & 16 & 37.2 \\
\hline$>4$ & 4 & 9.3 \\
\hline \multicolumn{3}{|c|}{ Hemoglobin, M \pm Ecart-type (g/dl) } \\
\hline$<10$ & 11 & 25.6 \\
\hline$>10$ & 9 & 20.9 \\
\hline \multicolumn{3}{|c|}{ Platelets, M \pm Ecart-type (g/dl) } \\
\hline$<150$ & 2 & 4.6 \\
\hline
\end{tabular}




\begin{tabular}{|c|c|c|}
\hline Variables & Effective (N) & Percentage \\
\hline $150-450$ & 17 & 39.5 \\
\hline$>450$ & 1 & 2.3 \\
\hline \multicolumn{3}{|c|}{ Ionogram } \\
\hline \multicolumn{3}{|c|}{ Sodium (mmol) } \\
\hline$<135$ & 6 & 13.9 \\
\hline $135-145$ & 15 & 34.9 \\
\hline$>145$ & 2 & 4.6 \\
\hline \multicolumn{3}{|c|}{ Potassium (mmol) } \\
\hline$<3,5$ & 7 & 16.3 \\
\hline $3,5-4,5$ & 15 & 34.9 \\
\hline$>4,5$ & 1 & 2.3 \\
\hline \multicolumn{3}{|c|}{ CRP (mg/dl) } \\
\hline$<6$ & - & \\
\hline$>6$ & 2 & 4.6 \\
\hline
\end{tabular}

Table 6: Distribution according to radiological signs.

\begin{tabular}{|lll|}
\hline Radiology & Effective $(\mathbf{N})$ & Percentage \\
\hline AWP & 3 & 7.0 \\
\hline IHDGC & 2 & 4.6 \\
\hline Aeocoly & 2 & 4.6 \\
\hline Diffuse grisaille & 1 & 2.3 \\
\hline Abdomen ultrasound & 21 & 48.8 \\
\hline Hemoperitoneum & 13 & 0.2 \\
\hline Hepatomegaly & 4 & 9.3 \\
\hline Pneumoperitoneum & 9 & 20.9 \\
\hline Splenomegaly & 4 & 9.3 \\
\hline Splenic rupture/fracture & 2 & 4.6 \\
\hline Subcapsular hematoma & 2 & 4.6 \\
\hline Abdominal scanner & 11 & 25.6 \\
\hline Hemoperitoneum & 8 & 18.6 \\
\hline Fluid effusion & 2 & 4.6 \\
\hline Aerocoly & 3 & 7.0 \\
\hline Eventration des handles & 2 & 4.6 \\
\hline
\end{tabular}

IHDGC- Inter-hepato-diaphragmatic gas crescent; AWP- Abdomn without preparation

Table 7: Distribution according to operative elements.

\begin{tabular}{|c|c|c|}
\hline Radiology & Effective (N) & Percentage \\
\hline \multicolumn{3}{|l|}{ Time to surgical intervention } \\
\hline$<12 \mathrm{H}$ & 23 & 54.8 \\
\hline $13-24 \mathrm{H}$ & 13 & 30.2 \\
\hline $25-48 \mathrm{H}$ & 6 & 14.3 \\
\hline \multicolumn{3}{|l|}{ Surgical technique } \\
\hline Laparotomy & 42 & 97.7 \\
\hline laparoscopy & 1 & 2.3 \\
\hline \multicolumn{3}{|l|}{ Incision } \\
\hline Median (sub/supraumbilical) & 42 & 97.7 \\
\hline Laparoscopic & 1 & 2.3 \\
\hline \multicolumn{3}{|l|}{ Anesthesia } \\
\hline Spinal anesthesia & 3 & 7.0 \\
\hline General anesthesia & 40 & 93.0 \\
\hline
\end{tabular}




\section{Radiological signs}

As shown in Table 6, abdominal ultrasound was the most common exam required and performed by patients, $48.8 \%$ of the time. She observed hemoperitoneum in $30.2 \%$, splenic affections in $18.5 \%$ (organomegaly, rupture, fracture, HSC) and pneumoperitoneum in $20.9 \%$ of cases. The abdominal CT scan was performed in $25.6 \%$ of patients, and explored the eventration in $4.6 \%$ of cases.

\section{Surgical intervention}

As it appears in Table 8, splenic affections (rupture, fracture, etc) were the most common $(41.9 \%)$. In the majority of cases (16/18), a total splenectomy was

\section{Treatment}

\section{Operative elements}

Total of $84.8 \%$ of abdominal trauma cases were managed surgically within 24 hours. The laparotomy route was used $100 \%$ of the time. In one of them, she assisted with an initially laparoscopic approach. In $93 \%$ of cases, the anesthesia was general (Table 7).

performed, and in 2 cases a splenic suture+hemostasis was performed. Resection+anastomosis was the treatment of choice for traumatic intestinal lesions, and cures (simple or prosthetic) were prescribed for cases of evisceration.

Table 8: Findings and surgical procedures.

\begin{tabular}{|c|c|c|}
\hline Variables & Effective (\%) & Surgical intervention \\
\hline Spleen & $18(41.9)$ & \multirow{4}{*}{$\begin{array}{ll}\text { - } & \text { Splenectomy (16) } \\
\text { - } & \text { Splenic surure+hemostasis (2) }\end{array}$} \\
\hline Splenic burst & $2(4.7)$ & \\
\hline Splenic fracture & $10(23.3)$ & \\
\hline Splenic rupture & $6(14.0)$ & \\
\hline Stomach & $2(4.7)$ & \\
\hline Gastric injury & $1(2.3)$ & - Gastric suture \\
\hline Omental evisceration & $1(2.3)$ & - Evisceration treatment+suture \\
\hline Small intestine & $15(34.9)$ & \\
\hline Duodenal perforation & $1(2.3)$ & \multirow{3}{*}{ - Intestinal resection+anastomosis } \\
\hline Jejunal perforation & $5(11.6)$ & \\
\hline Ileal wound & $2(4.7)$ & \\
\hline Mesenteric wound & $2(4.7)$ & - Mesenteric suture \\
\hline Hail-colic evisceration & $5(11.6)$ & - Evisceration treatment+suture \\
\hline Colon & $7(16.3)$ & \\
\hline Sigmoid laceration & $3(7.0)$ & - Resection/suture+anastomosis \\
\hline Post-operative eviscération & $2(4.7)$ & - Evisceration treatment+washing \\
\hline Colonic perforation & $1(2.3)$ & - Intestinal resection+anastomosis \\
\hline Giant eventration & $1(2.3)$ & - Prosthetic treatment \\
\hline Liver tumor rupture & $1(2.3)$ & - Arterial hemostasis \\
\hline
\end{tabular}

\section{Post-operative treatment}

Postoperatively, the infusion of fluids was prescribed systematically in all patients. Saline $9 / 1000$, glucose sera and ringer lactate were administered in $76.7 \%, 58.1$ and $72.1 \%$ of cases, respectively. The combination ceftriaxone+metronidazole+gentamicin was used $74.4 \%$ (32 cases). Some patients have been given other antibiotics like ampicillin, amoxicillin+clavulanic acid and even ceftriaxone in a combination. The most commonly used analgesics were Trabar/Tramadol injection (76.7\%), Acupan/Nefopam $20 \mathrm{mg} / 2 \mathrm{ml}$ injection $(74.4 \%)$ and Perfalgan $1 \mathrm{~g}$ injection $(60.5 \%)$. A PPI was added therapeutically almost systematically $(85.7 \%)$, as well as a low molecular weight heparin (LMWH) in $58.1 \%)$. Two patients $(4.8 \%)$ received a transfusion during the postoperative period.

\section{Postoperative evolution}

A total of 5 patients $(11.6 \%)$ with complications were noted. Parietal suppurations were recorded (1 case, $2.3 \%$ ); suture release (1 case, $2.3 \%)$, paralytic ileus (1 case, $2.3 \%), 2$ cases of anemia (4.6\%).

\section{DISCUSSION}

We found $21.2 \%$ (43 cases) of abdominal trauma in our series. This rate is statistically higher than those found by Arnaud et al in Montpellier, Ibrahima et al in Dakar, Dembele et al in Mali, who found 3.67\%, 4.34\%, 3.70\% respectively $(p=0,0102)$ cases of abdominal trauma. ${ }^{9-11}$ In the literature, road accidents resulted in serious lesions, with that of the spleen in first position, the same as found in our study where the spleen was the organ most affected (in $41.9 \%$ of cases) followed by lesions of the gastrointestinal tract (39.6\%). ${ }^{12-14}$ This could be explained 
by the upsurge in organized crime (physical assaults, armed conflicts) and accidents on the public highway (especially aboard motorcycle taxis) in our context.

Abdominal trauma in our series mainly affected adults between 20 and 39 years old, with 27 cases recorded $(63 \%)$. This rate is close to the data in the literature, where the age group most exposed to abdominal trauma is that between 21 and 30 years old, as observed in the studies by Arnaud et al in Montpellier (40\%), Ibrahima et al $(57.14 \%) .{ }^{9,11}$ Harouna et al on the other hand, observed a majority (35\% of cases) in children (5-15 years), and Karim et al $(39.5 \%)$ in $15-20$ years. ${ }^{12,15}$ These variations depend for each study on the traumatic causes in the patients.

The male sex was the most affected by abdominal trauma, in our series, with sex ration of 3.3. Some authors have found a predominance of men, but with a much higher sex ratio. This is the case with Sambo et al (7.17:1), Kambire et al (13:1), Ntundu et al (5.5:1). ${ }^{2,4,16}$ This predominance could be explained by the socioprofessional activity of men, making them more exposed than women. Regarding the etiologies of abdominal trauma, road accidents occupy the first place with $34.9 \%$ of consultations. Sambo et al found $33.63 \%$, Kambire et al- $53.6 \%$, thus joining other authors in their publication. ${ }^{2,4,16-18}$ This situation would be due to the state of the roads, alcohol consumption of drivers and the nonobservance of road prevention measures. ${ }^{7,16}$ Wounds in our series represented $27.9 \%$ (12 cases) and contusions $72.1 \%$ (31 cases). These data are also found by other authors such as Sambo et al (25.5\% of wounds), Ntundu et al (3/4 of bruises), Kambire et al (9/1cases were blunt trauma). 2,4,16 However, Raherinantenaina et al found a predominance of wounds $(58.2 \%)$ and Idriss et al found $80 \%$ of the penetrating diseases thus joining Gaudeuille in the Central African Republic and Mnguni in Durban in South Africa who had found respectively $75 \%$ and $90.2 \%$ of wounds due to the frequency of attacks by knives and firearms in large towns. ${ }^{19-22}$ The predominance of bruises in our study could be explained by the high number of road accidents.

The lesional assessment was performed preoperatively by a certain number of patients in our series. In fact, AWP was performed in $7.0 \%$ of cases, abdominal ultrasound $48.8 \%$ and abdominal CT scan in $25.6 \%$ of patients. These radiological examinations were sufficiently contributory because they made it possible to highlight cases of gas crescents under diaphragms, hemoperitoneum, ruptured spleen and other important signs. Raherinantenaina et al state that $60.8 \%$ of patients were unable to financially access radiological explorations, while Kambire et al acknowledged that the lesion assessment in his series was mostly intraoperative. ${ }^{4,19}$ This situation would either be due to either the poverty of the population, or also the lack of resources of the structures concerned. ${ }^{4,23}$
The organs affected in order were the spleen, small intestine, colon, stomach and liver in our series. Just as in our study the spleen, the hail and the colon occupy the $1 \mathrm{st}$, the 2 nd and the 3rd place, Kambire et al found exactly the same order with respectively $48 \%, 37 \%$ and $11.1 \%$ of the cases; we are joined by Sambo et al in whom the spleen and the small intestine were also the most frequently damaged organs with respectively $15 \%$ and $13 \%$ of cases. ${ }^{2,4}$ However, certain authors such as Sani et al, Sanu et al and Raherinantenaina et al find intestinal lesions (colic and/or hailstones) as a priority. ${ }^{19,24,25}$ Regarding management, all of our patients were operated, unlike other authors. Sambo et al noted $33.67 \%$ of patients who had an abdominal contusion, not operated. ${ }^{2}$ Kambire et al reported that surgical treatment concerned 27 of thier 28 patients, or $96.4 \%$ of cases, and Raherinantenaina et al $91.8 \% .^{4,19}$ These results that we found suggest that all the diagnostic and monitoring methods including MRI, CT and ultrasound were used systematically, some laparotomies could have been avoided.

We performed 16 splenectomies $(37.2 \%)$ or exactly $16 / 18$ cases of admitted spleen trauma, i.e. $89.5 \%$ of cases. This figure remains lower than that of certain authors such as Sambo et al with $17 / 18$ splenectomies $(94.44 \%){ }^{2}$ These figures may be further reduced if radiological monitoring could be systematic because cases of spontaneous healing of major splenic lesions are contacted. ${ }^{26} \mathrm{We}$ recorded postoperative complications with a morbidity of $11.6 \%$ with a single case of parietal suppuration and no death. This morbidity is much lower than those of $\mathrm{Ba}$ et al $(18.5 \%)$ and Kambire et al $(17.8 \%)$, however higher than the rates of Sambo et al $(8.16 \%)$ and Raherinantenaina et al $(3.6 \%)^{2,4,19,23}$ But unlike these authors we have not recorded any deaths, whereas Kambire et al reported$21.4 \%$, Raherinantenaina et al- 5.7\%, and Sambo et al$2.06 \%{ }^{2,4,19}$

\section{Limitations}

During our study, we encountered some limitations. Several factors prevented us from having a much larger sample: the journey of patients from the operating room to sometimes anarchic hospitalization; the operative reports which are sometimes poorly or not completed by practitioners preventing us from having certain information in their entirety, the high cost of examinations to be performed by patients, sometimes hampering the diagnosis with certainty.

\section{CONCLUSION}

Abdominal trauma remains quite frequent in our environment, representing $21.2 \%$ of abdominal emergencies. Road accidents are the main cause $(34.9 \%)$. Young people in general remain the most affected with men, the sex largely most affected. The spleen is the organ most frequently shocked, hence the high rate of splenectomies performed. However, it is important that 
all patients can benefit from the diagnosis as well as the monitoring offered by the various radiological methods. The incidence of postoperative complications remains high, despite the fact that we have not recorded any deaths.

\section{Funding: No funding sources}

Conflict of interest: None declared

Ethical approval: The study was approved by the Institutional Ethics Committee

\section{REFERENCES}

1. Isenhour JL, Marx J. Advances in abdominal trauma. Emerg Med Clin North Am. 2007;25(3):713-33.

2. Sambo TB, Hodonou MA, Allode SA, Mensah E, Youssouf M, Menhinto D. Aspects Epidemiologiques, Diagnostiques Et Therapeutiques Des Traumatismes Abdominaux À Bembéréké-Nord Bénin. European Scientific J. 2016;12(9):395-405.

3. Fakhry SM, Brownstein M, Watts DD, Baker CC, Oller D. Relatively short diagnostic delays $(<8$ hours) produce morbidity and mortality in blunt small bowel injury: an analysis of time to operative intervention in 198 patients from a multicenter experience. J Trauma. 2000;48(3):408-14.

4. Kambire JL, Ouedraogo S, Zida M, Ouedraogo S, Sanon BG. Abdominal Trauma: Epidemiological and lesional Aspects at the Regional Teaching Hospital Center of Ouahigouya, Burkina Faso. Rev Int Sci Med RISM. 2018;20(1):71-5.

5. Vivien B, Langeron O, Riou B. Closed abdomen trauma. National Congress of Anesthesia and Resuscitation. 2007;433-43.

6. Peitzman AB, Heil B, Rivera L, Federle MB, Harbrecht BG, Clancy KD, et al. Blunt splenic injury in adults: Multi-institutional Study of the Eastern Association for the Surgery of Trauma. J Trauma. 2000;49(2):177-87.

7. Chalya PL, Mabula JB. Abdominal trauma experience over a two-year period at a tertiary hospital in north-western Tanzania: a prospective review of 396 cases. Tanzan J Health Res. 2013;15(4):230-9.

8. Alastair CJ, Pierre JG. Abdominal trauma. In: John M, Graeme D, Kevin OM, eds. Surgical Emergencies. 1st ed. Italy: Blackwell Science; 1999: 224-236.

9. Arnaud JP, Turbelin JM. Acute abdominal pain: What investigations. EM Consolute. 1982;10:3.

10. Dembele B. Digestive surgical emergencies at the Kayes Regional Hospital (Mali) about 112 cases. Thesis Med Bamako. 2005;61:234.
11. Ibrahima G, Pape AL, Mamadou MT, Pape IN, Elhadji B, Mamadou DB. Pre-operative management of surgical emergencies. Pan Afr Med J. 2016;24:190.

12. Harouna Y, Ali L, Seibou A, Abdou I, Gamatie Y, Rakotomalala J. Two years of emergency digestive surgery at the national hospital. Med African Noire. 2009;48(2):50-4.

13. Lakhoo K, Bass D, Cywes S. Blunt splenic trauma in children. S Afr J Surg 2000;29(3):108-9.

14. Bordon LM Penetrating abdominal spear injuries. Centr Afr J Med. 1992;38(4):155-61.

15. Karim A. Activity report of digestive surgical emergencies at the prefectural hospital of Inezgane over 2 years 2014-2015. Faculty Med. 2017.

16. Ntundu HS, Herman MA, Kishe A, Babu H, Jahanpour FO, Msuya D, et al. BMC Surg. 2017; 19:69.

17. Menyar A, Abdelrahman H, Thani H, Zarour A, Parchani A, Peralta R, et al. Compartmental anatomical classification of traumatic abdominal injuries from the academic point of view and its potential clinical implication. J Trauma Manag Outcomes. 2014;8:14.

18. Gad MA, Saber A, Farrag S, Shams ME, Ellabban GM. Incidence, Pattern, and Factors Predicting Mortality of Abdominal Injuries in Trauma Patients N AMJ Med Sci. 2012;4(3):129-34.

19. Raherinantenaina F, Rakotomena SD, Rajaonarivony $\mathrm{T}$ et al. Blunt and penetrating trauma to the abdomen: retrospective analysis of 175 cases and review of the literature. Pan African Med J. 2015;20:129.

20. Idriss AM, Tfeil Y, Baba JS, Boukhary SM, Hamad B, Abdllatif $M$, et al. Abdominal trauma: five years'experience in National Centre Hospital, Mauritania. Open J Emerg Med. 2018;6(1):6.

21. Gaudeuille A, Doui DA, Ndemanga KJ, Sacko E, Nali NM. Abdominal trauma in Bangui (Central africa). Epidemiologic and et anatomical aspects. Mali Med. 2007;22(2):19-22.

22. Mnguni MN, Muckart DJ, Madiba TE. Abdominal trauma in Durban, South Africa: factors influencing outcome. Int Surg. 2012;97(2):161-8.

23. Ba SS. Traumatic perforations of the colon- Aspects at CHU. Beep. 2012;127:120.

24. Sani R, Ngo Bissemb NM, Illo A. Epidemiological, Diagnostic And Therapeutic Aspects national de Niamey-Niger. Med Afr Noire. 2004;51(7):399-402.

25. Sanou ML. Primary peritonitis- 57 caes. Anne University. 2008.

26. Diabate A. Traumatisme abdomen at hospital Somine Dolo. Anne University. 2002.

Cite this article as: Engbang JP, Chasim CB, Fouda B, Motah M, MoukouryTJK, Ngowe MN.

Epidemiology, diagnostic and management of abdominal trauma in two hospitals in the city of Douala, Cameroon Int Surg J 2021;8:1686-93. 